OPEN ACCESS

Citation: Giuliano Bobba, Moreno Mancosu, Franca Roncarolo, Antonella Seddone, Federico Vegetti (2021) Losers get sick? The effects of electoral defeat on perceptions of pandemic risk. Quaderni dell'Osservatorio elettorale Italian Journal of Electoral Studies 84(2): 79-91. doi: 10.36253/qoe-10749

Received: April 4, 2021

Accepted: July 29, 2021

Published: August 30, 2021

Copyright: () 2021 Giuliano Bobba, Moreno Mancosu, Franca Roncarolo, Antonella Seddone, Federico Vegetti. This is an open access, peer-reviewed article published by Firenze University Press (http://www.fupress.com/qoe) and distributed under the terms of the Creative Commons Attribution License, which permits unrestricted use, distribution, and reproduction in any medium, provided the original author and source are credited.

Data Availability Statement: All relevant data are within the paper and its Supporting Information files.

Competing Interests: The Author(s) declare(s) no conflict of interest.

Orcid

GB: 0000-0001-9724-5650

MM: 0000-0002-3017-4066

FR: 0000-0001-5772-9351

AS: 0000-0002-9490-7599

FV: 0000-0002-1541-114X

\section{Losers get sick? The effects of electoral defeat on perceptions of pandemic risk}

\author{
Giuliano Bobba ${ }^{1,2}$, Moreno Mancosu ${ }^{1,2}$, Franca Roncarolo ${ }^{1}$, \\ Antonella Seddone ${ }^{1}$, Federico Vegetti ${ }^{1, *}$ \\ ${ }^{1}$ University of Turin, Italy \\ ${ }^{2}$ Collegio Carlo Alberto, Turin, Italy \\ * Corresponding Author. Email: federico.vegetti@unito.it
}

\begin{abstract}
Research in political behavior shows that citizens update their past perceptions and future expectations over several phenomena depending on whether their favorite party wins or loses the elections. This bias is explained by different psychological mechanisms triggered by individuals' attachment and trust in political parties. In this paper we investigate whether such a winner-loser effect conditions people's concerns about the Covid-19 pandemic. We leverage the occurrence of regional elections in six Italian regions in September 2020, right at the onset of the second wave of the pandemic in the country, to test whether supporting a candidate who won/lost the elections affects (1) people's fear to get sick with Covid-19, and (2) their expectation about the gravity of the upcoming second wave. Given that the public healthcare system in Italy is managed by the regions, we expect supporters of the losing candidate to lose trust in the region's ability to deal with the pandemic, hence increasing their personal concerns. We test this expectation using pre-/post-election panel data, and employing respondents from the other regions who voted at a concurrent referendum as a placebo group. Our results show that, while overall concerns tend to decrease from the first to the second wave, for elections losers they remain unchanged. This indicates that losing an election, albeit second-order, can affect citizens' outlook on future events in domains that are largely beyond political control.
\end{abstract}

Keywords: Covid-19, partisan bias, risk perception, 2020 Italian regional elections.

\section{INTRODUCTION}

The COVID-19 pandemic has had an enormous impact in nearly every aspect of public and private life worldwide. In addition to dramatically modifying citizens' everyday routines, it has also had consequences in the social, economic, and political realm. On the one hand, some studies have suggested that the global health emergency has contributed to enhance the public support for incumbent governments, who took measures to face the pandemic crisis (Bol et al., 2020). On the other hand, several studies suggest that people have reacted to the pandemic emergency clinging on to their own preexisting beliefs (Calvillo et al. 2020). A relevant instance of this process is represented by the politicization of the crisis, and the asymmetric ways in which parti- 
san supporters have responded to the pandemic. Recent research has demonstrated that parties and citizens, more than rallying around the flag and pursuing the most efficient possible strategy to exit the public health emergency, addressed the pandemic-related policies and public actions by applying a partisan frame (e.g., Druckman et al., 2020; Allcott et al., 2020). Likewise, people have largely aligned themselves to narratives proposed by their own favorite parties, accepting or refusing policy proposals and recommendations based on their partisan priors. Other literature suggests that even the reactions to government measures and restrictions have been affected by partisanship, meaning that citizens' behavior in terms of compliance can be explained by their previous political beliefs (Painter and Qiu, 2021; Grossman et al., 2020).

As Barrios and Hochberg $(2020,1)$ pointed out, "[e] ven when - objectively speaking - death is on the line, partisan bias still colors beliefs about facts". This behavior is particularly puzzling since, as long as the level of emergency has escalated, people and parties have increasingly realized that the pandemic is a complex phenomenon, in which responsibilities of the political power, the economic elites, and the scientific community are blurred, and, thus, simple political answers are rarely effective per se.

Scholars dealing with partisanship and political behavior have emphasized that the winner/loser status might influence individuals' attitudes and beliefs (e.g., Martini and Quaranta 2019; Hansen et al., 2019). For instance, previous studies have found that people whose favorite party/candidate loses an election tend to predict a worse national economic performance, or to adjust their past evaluations, depicting a "better past" than they originally saw before the electoral loss (Quaranta et al., 2020). Likewise, literature emphasizes that losers in electoral competitions are generally less satisfied with democracy with respect to winners (Anderson and Guillory 1997; Hansen et al., 2019). These findings provide an example of the fact that partisanship represents an important driving force for people's beliefs and attitudes on several political and societal issues.

This study aims at expanding this stream of research by showing that the electoral winner/loser status can affect the evaluation of the potential risks that one can incur during a global pandemic. Precisely, we test whether being the loser or the winner of an electoral competition changes individuals' perceptions with respect to (a) the societal risk, namely the perception that the pandemic will worsen, and (b) the individual risk, namely the fear to be personally infected with COVID-19. Building on previous research on winner/loser effects, we argue that voters whose party lost an election will be more likely to expect a suboptimal response to the health emergency in the future, leading to worsening expectations about the progress of the pandemic (and hence higher societal risk) and, in turn, a higher chance to get infected (higher individual risk).

We test our expectations by focusing on the 2020 Regional election cycle in Italy, which provides an excellent case study for our purposes given the particular institutional setting that Italy provides. According to the Italian constitution, regional governments are responsible (and accountable) for the public health care in their territory. For this reason, we expect regional elections - despite being second-order elections - to be extremely salient for what concerns the possibility of increasing/ decreasing perceived risk during the pandemic. In addition, the regional elections held in September 2020 offer a further advantage for testing our expectations, as on the same date all Italian citizens were called to vote for a constitutional referendum. Because of both these institutional and situational characteristics, the Italian case in 2020 is ideal to to estimate the change in perceived societal and individual risk for people who won and lost the election, and people who were not potentially subject to a change in regional government (this latter case representing thus a sort of placebo group in our research design).

Our hypotheses are tested using a panel survey observing the perceived societal and individual risk in a sample of Italian respondents before and after the regional elections held in six Italian regions in September 2020. In particular, we use a pre-post longitudinal design: attitudes toward risk perceptions are collected both before and after the elections, making it possible to assess the effect that winning or losing the regional elections has on the change in perceived risk. Our results show that the electoral losers tend to have higher perceived risk with respect to winners and non-exposed, and that the effect is stronger for societal risk perception. The article is organized as follows: section 2 discusses the recent literature investigating the linkage between COVID-19 pandemic and political attitudes, it details the case study and presents the hypotheses to be tested. Section 3 focuses on the research design, measures and variables, while the fourth section describes the analyses. The final section discusses the main findings and their contribution to the literature.

\section{BACKGROUND. THE COVID-19 PANDEMIC AND POLITICAL ATTITUDES}

Recent political research has explored the association between political attitudes and reactions to 
the COVID-19 crisis. In particular, some studies have investigated the impact of partisan biases on a number of attitudes and behaviors related to the pandemic (e.g. Allcott et al., 2020; Druckman et al., 2020; Grossman et al., 2020). By looking mainly at the US, studies have shown that, for instance, conservative people tend to perceive a lower risk of being infected by the new coronavirus (Barrios et al., 2021). Similar results, again based on the US case, are also found by Grossman et al. (2020). They found that government recommendations about reducing mobility were by far more effective in Democratic-leaning counties than in Republican-leaning counties, confirming the central role of partisanship in affecting individuals' propensity to engage in social distancing. Likewise, Painter and Qiu (2021) found, looking at geolocation data sourced from smartphones, that residents in Republican counties were less likely to align with government mandates in response to the COVID-19 outbreak. Strictly related to this result, other findings demonstrate, by using the geotracking of several million smartphones per day, that citizens who voted for Donald Trump in 2016 were also less keen to observe social distancing compared to former Hillary Clinton voters (Gollwitzer et al., 2020). Finally, other studies have found that Republicans are less prone to get vaccinated against COVID-19 with respect to Democrats (Kreps et al., 2020).

This empirical evidence (mainly observational and US-based) is generally interpreted in the light of several political and communication-based mechanisms producing partisan biases both in normal conditions and in cases of emergency. All these studies highlight a strong effect of the partisan cues that citizens received. It is worth noticing that conservative politicians and commenters (including Donald Trump himself) have signaled, especially during the first wave of the pandemic, that the new coronavirus threat was largely overestimated by the scientific community. It is not surprising thus that Trump supporters have been more skeptical about the possible negative effects of COVID-19 and, thus, behaved in a less careful way compared to Democrats (Graham et al. 2020; Hill et al. 2020). Likewise, studies suggest that Republicans are also more prone to be concerned about the vaccines' campaign and to believe in different conspiracy theories about COVID-19, as a result of the Trump public statements downgrading the seriousness of the pandemic (Hornsey et al. 2020). Consistently, it is reasonable to expect that Democrats have been more likely to blame the former president for the COVID-19-related issues compared to Republicans. Scholars have argued that, on the voters' side, the psychological mechanisms generating these empirical phenomena are related to partisan motivated reasoning (see Taber and Lodge, 2006). According to this process, when individuals evaluate new information, they are not much motivated to be accurate as they are to defend their pre-existing political preferences. To do so, citizens tend to accept and even actively look for information that is congruent with their own partisan beliefs, while they are more skeptical when they encounter incongruent information. As the aforementioned research shows, even in a dramatic situation such as a global pandemic, people prefer partisan consistency over accuracy.

Partisan biases also occur when people are asked to evaluate the responsibilities (or merits) of their government, and the COVID-19 emergency is no exception (Ward et al., 2020). By using different observational and experimental pieces of evidence in the US, Graham and colleagues (2021) demonstrate that partisan blame attribution has been particularly strong during the pandemic. Republicans exposed to positively-valenced information (e.g., successful actions aimed at reducing the new coronavirus spread) tend to attribute the responsibility to Trump. Conversely, when exposed to negativelyvalenced information, they tend to exculpate him. Likewise, Democrats are significantly more likely to do the opposite, by blaming Trump for negatively valencedinformation and attributing responsibility for positivelyvalenced actions to third parties (the healthcare system or other non-political institutions).

To our knowledge, however, these effects have been observed only at the national level, without looking at their possible local determinants. In other words, scholarship has focused on the relationship between COVID19-related attitudes and behaviors and the political color of the national government. However, the COVID-19 outbreak has had very specific territorial features, both in terms of contagion rates (e.g. local variants) and with respect to the capacities of the healthcare system dealing with the emergency (e.g., pressure on intensive care units, hospital equipment). In this respect, local governments play (and have played) a crucial role in handling the emergency. Hence, it is of great importance to investigate whether local governments' political color can affect citizens' perceptions related to the pandemic. To answer this research question, in this study we leverage a research design based on the so-called "winnerloser effect" on citizens' perceptions. Precisely, we ask whether being among the winners or the losers of an election might predict people's expectations about the future development of the pandemic, and their concern for their own health. 
Winner-loser electoral status and societal perceptions

People witness reality from their own position in the social and political landscape, and it is quite straightforward to argue that different points of view contribute to shape citizens' perceptions of reality. For instance, a large strand of literature has investigated that evaluations of the economy might be biased by the education level, knowledge, interest in politics or partisanship (e.g., Bisgaard 2015; Enns et al., 2012; Lewis-Beck et al., 2008). Another strand of literature emphasized that the electoral status, namely, the fact of being a supporter of the winner or the loser of an electoral competition, might shape people's perceptions on different societal and political issues. The literature on the effects that electoral status has on several attitudes and behaviors is particularly broad. Voting for the winning or losing party in an electoral competition has been proved to affect people's perception of the country's economic performance (Anderson et al., 2005), with winners evaluating it more positively and losers more negatively. Other studies have also demonstrated that satisfaction with democracy decreases among those voters supporting politicians/parties losing the electoral competition (Blais and Gelineau, 2007; Chang et al., 2014; Martini and Quaranta, 2015; Dahlberg and Linde, 2017). Further implications concerning the electoral status models have been developed, among others, by Curini and colleagues (2012; 2015), who demonstrated that satisfaction with democracy is a function of both historical winner-loser records (namely, having been winner-loser for more than one election), and ideological proximity between voters and parties. Other studies have investigated more in depth the effects that electoral status might have on other dependents variables, such as efficacy (Curini et al., 2021; Davis and Hitt, 2019). Literature has also investigated the way in which people experience themselves as winner or loser of the electoral competition, finding that this latter is a combination of parties' performance expectations and actual electoral results (see, for instance, Plescia, 2019).

As it is possible to see, the literature has addressed in depth all the elements and concepts that produce the theoretical argument. The theory identifies two mechanisms that might explain this empirical evidence. The first relates to bounded rationality (Quaranta et al., 2020; Lau and Redlawsk, 2001; Lupia and McCubbins, 1998). Since people do not have enough information to predict efficiently the possible consequences of the victory of one party with respect to another, they rely on heuristics allowing them to form an opinion. Because of mechanisms of selective exposure to political information, people's evaluations are still rational. They genuinely believe that opposing parties/leaders winning elections might lead to worse economic/democratic performances, and this is the case because their main sources of information are consistent with that opinion. A second mechanism centers around the emotional response to a possible victory/defeat of the electoral competition (Kunda, 1990; Leeper and Slothuus, 2014). In this case, the perceptions of the economic outcomes might be affected by the aforementioned motivated reasoning, which is driven by the disappointment over the defeat. Winning and losing - that is, being governed by the preferred party/leader or not - might affect people's need for cognitive consistency, providing strong cues leading to optimist/pessimist predictions of the economy. Finally, an additional element to take into account is negativity bias. A large amount of research (e.g., Baumeister et al., 2001; Soroka, 2014) has shown that negative information might be more effective in changing attitudes and behavior with respect to neutral/positive one. Consistent with this argument, research shows (e.g. Quaranta et al., 2020) that voters experiencing electoral defeat are more likely to see a decrease of their economic evaluation with respect to winners and non-voters.

This study starts from one main standpoint. We argue that pessimism following an electoral defeat (and, in a lesser way, optimism following an electoral victory) can be expanded outside the realm of economic and strictly political evaluations. We will thus test systematically whether being a winner or a loser in an electoral competition leads to more optimistic or pessimistic opinions concerning the possible risks related to the pandemic, and the concern to be personally infected.

Drawing upon the literature exposed above, we expect a mechanism that is a combination between the bounded rationality and the motivated reasoning arguments. We argue, indeed, that people losing the electoral competition are likely to expect a worse performance in handling the pandemic by who is in office. As a result, we expect that losers of an electoral competition will be more inclined to be pessimistic about future developments of the pandemic, while winners should be more optimistic. People experiencing a political opponent winning regional elections in a situation of pandemic crisis, indeed, have quite valid reasons to be concerned. The President of the Region has, as stressed above, a certain authority over the healthcare system: if one believes that a candidate is unfit to guide the region, the most immediate reaction to his/her victory will be to re-evaluate the potential risk that a possible new wave of the pandemic will be kept under control. 


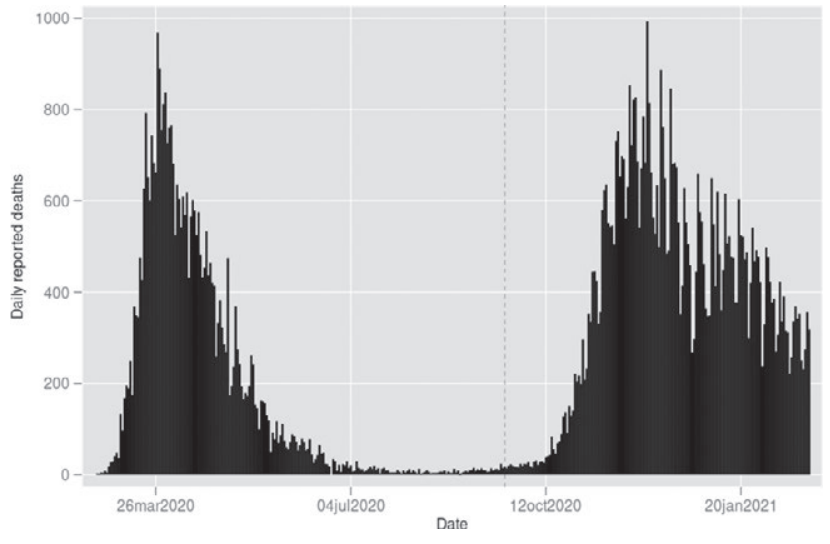

Figure 1. 2020 elections and pandemic data - death toll (the vertical line represents the election days).

Regional elections and constitutional referendum in Italy, September 2020

The regional elections of September 2020 in Italy represent an ideal case for us to test our expectations. On September 20 and 21, Italian citizens were called to vote for a constitutional referendum for the reduction of the number of MPs in Italian Parliament. In addition, during the same round of voting, regional elections were held in six regions (Campania, Liguria, Marche, Puglia, Toscana, and Veneto). It is important to note that the end of September 2020 was a period of relative stability of the COVID-19 pandemic in Italy. At that time, the possibility of a second wave of the pandemic was still a matter of debate, and, while likely, it was not sure that the magnitude of a possible second wave would be similar to what happened in the first wave. Figure 1 shows the death tolls from a longitudinal perspective, allowing to better understand the phase in which the election took place (see the vertical dashed line representing the election days) ${ }^{1}$.

Regional elections are usually interpreted as second-order elections (SOE), namely, elections perceived by citizens and parties as less important. Accordingly, regional elections are usually characterized by low turnout levels if compared with general elections. Indeed, citizens are said to have fewer incentives to participate and, moreover, their preferences will merely reflect the preferences formed by looking at national politics (see Reif and Schmitt, 1980). However, some scholars have suggested that the SOE interpretative framework should not be generalized (Schakel and Romanova 2018; Dan-

\footnotetext{
${ }^{1}$ The COVID-19-attributed deaths are based on the author's elaboration of Civil Protection data available at https://github.com/pcm-dpc/ COVID-19
}

doy and Schakel 2013; Mancosu and Vezzoni, 2018): literature has identified some contextual factors at the institutional level (e.g. electoral rules; the election cycle) that may contribute to shaping the perceived salience of regional elections (Dandoy and Schakel 2013). Italy, in this respect, represents a very privileged point of view. Scholars tend to agree that the SOE paradigm could explain many electoral and participative dynamics underlying Italian regional elections - especially in the First Republic (Bolgherini and Grimaldi 2017; Tronconi 2015; Tronconi and Roux 2009). Nonetheless, literature is also consensual in saying that, since the 1990s, the introduction of new powers and prerogatives at the regional level, the increase in regional autonomy, and the change of the electoral rules toward a higher prominence of presidential candidates, often supported by personal electoral lists, have emphasized the heterogeneity among regions, challenging the very idea of the SOE framework (Massetti 2018; Massetti and Sandri 2013; Vampa 2015). In the regional elections of 2020, these arguments are even more salient as, according to the Italian Constitution, the management of the public healthcare system is in the hands of the regions (Vampa 2021a; Vampa 2021b). The regional government, in other words, is entitled to handle healthcare policy, resulting in huge differences in regional healthcare performances in Italy (see for instance Nuti and Seghieri, 2014; Riganti, 2021). The direct responsibility of the regional government in dealing with the health emergency makes these regional elections extremely salient (De Sio, 2020). In terms of political accountability, the regional elections of September 2020 have been an occasion for the citizens to choose, albeit indirectly, those who are responsible for the regional health policy, and thus for several pandemic-related policies (e.g., contagion prevention, restrictions, vaccines administration, etc.).

\section{Hypotheses}

We expect that the winner/loser effect observed by previous literature, usually tested in the context of national economic/political predictions and evaluations, can be applied to voters' expectations about the performance of the healthcare system, under the responsibility of the regional government. As a consequence, voters supporting the defeated candidate might see the victory of the political opponent as an indicator of potential future negative performance. Given the regional responsibility over the health matters, a disappointing electoral outcome may eventually undermine the previouslyplanned responses to the pandemic. Accordingly, the first hypothesis reads as follows: 
H1. Evaluations of the pandemic risk at the societal level will be more optimistic among winners of the electoral competition with respect to losers.

As discussed above, in an emergency context, regional healthcare systems are crucial in dealing with possible future waves of the pandemic. Although literature dealing with economic evaluations have rarely reported effects of electoral status on evaluation of citizens' personal lives, we hypothesize that, in this case, the loser status might also affect people's expectations about the impact of the coronavirus on their own health. Defeated voters might be more likely to consider that wrong policies carried out by an incompetent regional government will increase their own risk of being infected by the new coronavirus. Therefore, hypothesis 2 reads as follows:

H2. Evaluations of the pandemic risk at the individual level will be more optimistic among winners of the electoral competition with respect to losers.

\section{DATA, VARIABLES, DESIGN}

We test our hypotheses relying on the two waves collected in 2020 of the on-line panel of the Italian National Election Study (ITANES)-University of Milan. The first wave of the panel was collected during the election campaign for the 2013 General Elections. Each year, two waves of the panel have been collected, usually one before and one after the main electoral events of the year. The data collection also included the two constitutional referenda (held in 2016 and 2020) and the regional elections (held in 2015 and 2020) that took place over the period. Interviews were administered to respondents through CAWI (Computer-Assisted Web Interview) mode. Respondents have been selected from an opt-in community (maintained by SWG, a private Italian research company). All the waves of the panel aim at reproducing the quotas for age, gender, and geographical distribution of the Italian population. Our study relies on the last two waves of the panel, collected shortly before and after the Constitutional Referendum of 20-21 September 2020. Overall, respondents who have been interviewed in both the waves and produced nonmissing responses were 2,932 .

The phenomenon that we are interested in is the citizens' perception of the risks associated with the COVID-19 pandemic. We focus on two specific risk assessments: (1) the societal risk, namely the perception that the pandemic will improve or worsen in the near future at the national level; (2) the individual risk, namely the self-assessed chance to contract the COVID-19 infection in the near future. We measure these two assessments using two survey items. The question used to observe societal risk perception asks the respondents how likely it is that there will be in the immediate future a pandemic wave similar to the one of March-April 2020. The answer categories range from 0 ("impossible") to 10 ("certain"). We have to keep in mind that the question has been asked around the elections, which were held on 20-21 September 2020, right in between the two pandemic waves. At that stage, in fact, the possibility of a second wave, although widely recognized as probable, was not certain. As Figure 1 reported above illustrates, the end of September coincides exactly with the final moments of the between-waves period. The second item assesses the individual risk perception, asking the respondents to state how likely it is that they will ever get COVID-19. As above, response categories were organized on a $0-10$ scale, where 0 indicates "impossible" and 10 "certain". To be sure, the two indicators are to a certain extent related to each other. We can expect that, the more the pandemic is expected to hit the country violently in the following weeks/months, the more people will be likely to perceive the risk of being infected. However, the two indicators observe two different types of assessment, one (individual risk) more concrete and influenced by a plethora of individual factors not easy to observe, and the other (societal risk) more abstract and closer to a political evaluation. ${ }^{2}$ Importantly, these two variables were observed before and after the elections, or in other words, people had to provide a risk assessment on the two dimensions before knowing for sure who would be the winner and who would be the loser. This allows us to observe the change in societal and individual risk assessment for each respondent individually, by calculating the crude difference between the post-election and the pre-election score.

The main independent variable of our interest refers to the winner/loser status of respondents after the election. In the post-election wave, people who reside in the regions holding the elections were asked which presidential candidate they voted for. This variable has been recoded into three categories, for three groups of voters: (A) the "placebo group", corresponding to voters residing in regions where there were no regional elections, ${ }^{3}$ (B) the voters of the winning candidate at the regional

\footnotetext{
${ }^{2}$ In addition, we can also stress that the first-order correlation between the two variables is particularly low (Pearson's $r=.20$ )

${ }^{3}$ In order to simplify the structure of the variable, people who declared to reside in the 6 regions in which regional elections were held and did not declare a vote for any presidential candidate were recoded as citizens who were not exposed to any regional election, and thus coded together with the placebo group.
} 
election, and (C) the voters supporting the losing candidates at the regional election.

Our regression models (see below) also include a set of control variables such as gender, age, educational level (coded as "primary", "secondary" and "tertiary" education), municipality size (divided in "under 10.000", "from 10.000 to 100.000 ", "over 100.000 inhabitants"), left-right self-placement (coded as "left", "center-left", "center", "center-right", "right", and "not located"), geopolitical zone (subdivided in "north-west", "north-east", "center", "south", and "islands"), interest in politics (a 4-point scale going from "not interested at all" to "very interested in politics"), working conditions (a dummy variable with "Currently employed" and "Currently not employed" as answer categories), and party identification (a dummy variable assessing whether respondents perceive themselves to be "close" to a party or not). ${ }^{4}$ Table A2 in the Supplementary material presents descriptive statistics of the variables involved in the analysis.

According to our hypotheses, once individuals get to know that their candidate won or lost the regional electoral competition, they will update their perceptions of societal and individual risk. We will employ a set of multilevel linear models to assess the effects of an individual's winner/loser status on their change in risk perception $^{5}$. In addition to the control variables, our main independent variable (the winner/loser status) allows us to assess the change in risk perceptions for the three groups (winners, losers, and not exposed to a regional election). Such a design gives us strong evidence about the mechanisms that lead to changes in the citizens' attitudes towards the pandemic. Given the importance of regional variation in our design, in this study we opt for a multilevel random-effects model in which people are nested into regions.

\footnotetext{
${ }^{4}$ Given the specific focus of the paper, we did not include in the analyses any variable accounting for the referendum results. Nonetheless, as a robustness check, we tested the same models including a variable observing the winner/loser status of respondents for what concerns the referendum. The coefficient of this variable is not statistically significant. This is not surprising given the topic of the Constitutional referendum. Lacking any real implications for the management of the pandemic, there are no clear effects on the respondents' expectations regarding the future of the pandemic. For further details, see Table A1 in the Supplementary Material.

${ }^{5}$ We employ a multilevel regression model because the data generating process that we assumed is intrinsically hierarchical, with individual differences being partly ascribable to differences in regional contexts. However, a multilevel model is not strictly necessary in our case: the Likelihood Ratio test of the multilevel model vs. linear regression produces a non-significant difference in model fit (this is true for both the empty and the complete model), meaning that the between-region variation is negligible in proportion to the overall variance. In this case, fitting a multilevel model is just a further theory-driven control, based on our assumptions on the data-generating process.
}

Overall, this estimation strategy resembles a difference-in-differences (DID) design (see Wooldridge, 2013). DIDs estimate the effects of treatments on a dependent variable by comparing the average change from $t_{0}$ to $t_{1}$ in the dependent variable. This modeling strategy relies on the assumption that the treatment that people receive after the referendum - "becoming" a winner or a loser is comparable with an "exogenous shock", not correlated with the evaluations in the pre-election wave. A violation of this assumption might be related to the expectations that voters have on the actual result of the elections. If it is obvious (or very likely) that a candidate will win the elections, voters might adjust their risk assessment already during the pre-election wave, leading to an underestimation of the effect. The bias, however, will reduce the possibility to observe a significant effect, producing a type II error (more conservative than the type I error).

\section{RESULTS AND DISCUSSION}

Table 1 shows coefficients of the two models.

An interesting result is that almost no coefficients of the control variables have strong and significant effects on the change in risk perceptions (this is a naive corroboration of the fact that the design might be intended as a quasi-experimental one). Only people living in large cities tend to be more concerned about a second pandemic wave between the pre- and the post-election measurement. Further, the models present a significant (although quite small) coefficient related to left-right self-placement, interest in politics, and working conditions. Our variables of interest, on the other hand, are significant. For what concerns the perceived societal risk (namely, the probability of a second wave as harsh as the first one) supporters of the winning candidate have a negative coefficient with respect to the losers. This indicates that those respondents are "less certain" that there will be a second wave of COVID-19 infections in the near future than they were before the elections. Furthermore, our "placebo" group - namely, people living in regions where there were no regional elections - has a negative coefficient. In general, electoral losers after the elections tend to perceive a higher risk than both non-exposed to regional elections and winners. $\mathrm{H} 1$ is thus confirmed. The loser status, in other words, increases the negative outlook about the pandemic. The story is different when investigating individual risk perceptions (Model 2). In this case, indeed, the negative figure refers to respondents non-exposed to regional elections, and it is worth noticing that the coefficient is even smaller with respect 
Table 1. Two multilevel regression models studying individual and societal pandemic risk in the future.

\begin{tabular}{|c|c|c|c|c|}
\hline \multirow{2}{*}{$\begin{array}{l}\text { Dep. variable } \\
\text { Indep. Variables }\end{array}$} & \multicolumn{2}{|c|}{$\begin{array}{l}\text { Model } 1 \\
\text { Societal }\end{array}$} & \multicolumn{2}{|c|}{$\begin{array}{l}\text { Model } 2 \\
\text { Individual }\end{array}$} \\
\hline & Coef. & S.E. & Coef. & S.E. \\
\hline \multicolumn{5}{|l|}{ Electoral status (ref. Loser) } \\
\hline No regional election held & $-0.28^{\star *}$ & $(0.12)$ & $-0.19^{\star}$ & $(0.10)$ \\
\hline Winner & $-0.35^{\star *}$ & $(0.14)$ & -0.14 & $(0.12)$ \\
\hline Gender: Woman (ref. Man) & 0.01 & $(0.08)$ & 0.04 & $(0.07)$ \\
\hline Age & 0.00 & $(0.00)$ & 0.00 & $(0.00)$ \\
\hline \multicolumn{5}{|l|}{ Education level (ref. Primary) } \\
\hline Secondary & -0.08 & $(0.13)$ & -0.16 & $(0.11)$ \\
\hline Tertiary & -0.09 & $(0.14)$ & -0.13 & $(0.11)$ \\
\hline \multicolumn{5}{|c|}{ Municipality size (ref. Under 10k) } \\
\hline $10 \mathrm{k}-100 \mathrm{k}$ & $0.21^{\star \star}$ & $(0.10)$ & 0.08 & $(0.09)$ \\
\hline Over $100 \mathrm{k}$ & $0.27^{\star *}$ & $(0.11)$ & -0.00 & $(0.09)$ \\
\hline \multicolumn{5}{|c|}{ Left-right self-placement (ref. Left) } \\
\hline Center-left & 0.14 & $(0.13)$ & 0.01 & $(0.11)$ \\
\hline Center & $0.35^{\star *}$ & $(0.17)$ & -0.00 & $(0.14)$ \\
\hline Center-right & 0.12 & $(0.14)$ & 0.12 & $(0.11)$ \\
\hline Right & 0.20 & $(0.17)$ & 0.12 & $(0.14)$ \\
\hline Not located & 0.13 & $(0.17)$ & -0.11 & $(0.14)$ \\
\hline Interest in politics & $0.11^{\star *}$ & $(0.05)$ & 0.06 & $(0.04)$ \\
\hline $\begin{array}{l}\text { Party identification (ref. not } \\
\text { identified) }\end{array}$ & -0.04 & $(0.10)$ & $-0.13^{*}$ & $(0.08)$ \\
\hline $\begin{array}{l}\text { Working conditions (ref. } \\
\text { Employed) }\end{array}$ & $0.18^{\star *}$ & $(0.08)$ & 0.03 & $(0.07)$ \\
\hline \multicolumn{5}{|c|}{ Geo-political zone (ref. North-West) } \\
\hline North-East & 0.02 & $(0.11)$ & -0.08 & $(0.09)$ \\
\hline Center & 0.01 & $(0.12)$ & 0.08 & $(0.10)$ \\
\hline South & -0.11 & $(0.12)$ & -0.07 & $(0.10)$ \\
\hline Islands & -0.01 & $(0.13)$ & -0.10 & $(0.11)$ \\
\hline Constant & $-0.82^{\star \star}$ & $(0.32)$ & -0.07 & $(0.27)$ \\
\hline Lvl-2 var & $0.00^{* * *}$ & $(0.00)$ & $0.00^{\star * *}$ & $(0.00)$ \\
\hline Lvl-1 var & $0.64^{* * *}$ & $(0.01)$ & $0.43^{* * *}$ & $(0.01)$ \\
\hline Observations & \multicolumn{2}{|c|}{2,586} & \multicolumn{2}{|c|}{2,446} \\
\hline Number of groups & \multicolumn{2}{|c|}{20} & \multicolumn{2}{|c|}{20} \\
\hline
\end{tabular}

Standard errors in parentheses. ${ }^{* *} \mathrm{p}<0.01,{ }^{* *} \mathrm{p}<0.05,{ }^{*} \mathrm{p}<0.1$

to Model 1). There is thus no significant difference between winners and losers, leading us to reject $\mathrm{H} 2$.

Linear predictions obtained from the two multilevel models, shown in Figure 2, provide a clearer picture of the change between the two waves among the three groups. As the figure shows, respondents supporting a losing party display no significant change between the first and the second wave in both models, implying that, on average, the election defeat did not prompt them to update their individual and societal risk assessment.

Quite surprisingly, on the other hand, we find a general reduction in perceived risk on both domains in the placebo group, namely those respondents living in regions not having regional elections in that cycle. Given their non-involvement and their number (they are the largest portion of the sample), respondents in this group are to be regarded as the reference point, suggesting a general improvement of the individual and societal risk perceptions among Italian citizens in the second half of September 2020. This might be due to the fact that, from the second half of August through September, the number of new infected individuals reported daily had experienced a rise as compared to the summer, which nevertheless was not following an exponential growth curve. In other words, the fact that the growing spread of the virus was visible but (apparently) under control might have given all citizens a boost in optimism regarding how the next months could have looked like. In fact, it was from the beginning of October that the number of daily observed infections started growing exponentially.

Finally, we find that respondents in the winners group show a significant reduction in societal, but not in individual, risk perception. This suggests that winning the elections did lead to higher optimism, in the form of a lower concern about the societal risk related to the pandemic, but only to the extent that optimism was growing among all Italian citizens. The electoral winners of the regional elections of September 2020 observed in our sample do not look significantly different from the baseline, while the electoral losers do. This suggests that losing an election might have a stronger impact on citizens' attitudes and perceptions than winning, confirming the presence of a general negativity bias in the effect that electoral competitions can have on the citizens.

To be sure, this analysis presents some limitations. First, even though we controlled for the possible impact of the concomitant referendum - and found no significant effects - a possible alternative model could have included interactions between winners and losers of both regional elections and referendum. Unfortunately, the small size of the sample does not allow to run reliable analyses for tackling this dimension. Second, some of our inconclusive findings, such as the lack of significant difference between winners and losers on the individual risk perception, or the lack of significant difference between winners and the group of respondents from non-affected regions, might be due to the relatively low expectations about an electoral change in those regions. 2020 regional elections did indeed lead to quite unsurprising results: the margin between the 

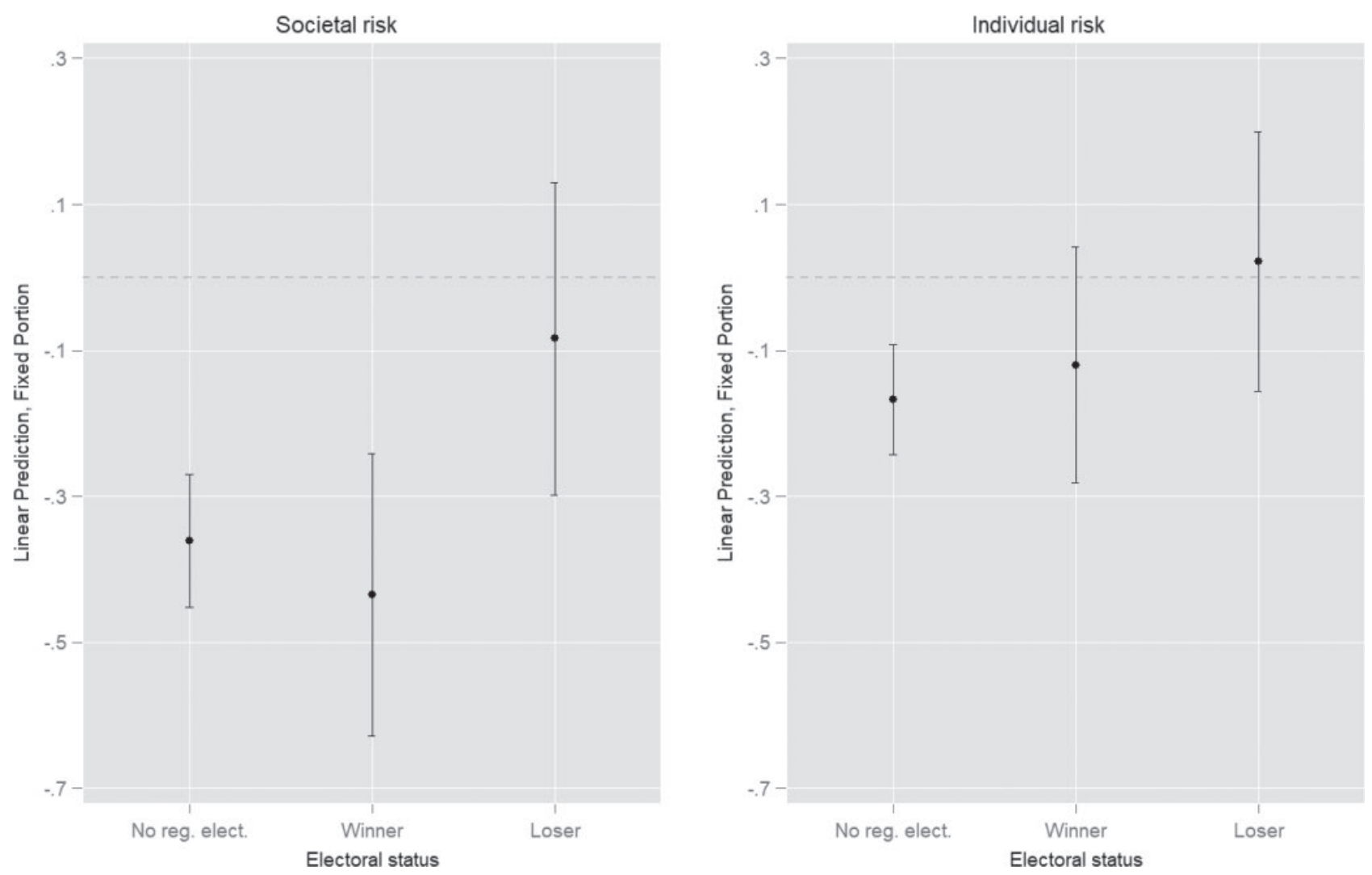

Figure 2. Linear predictions for models 1 (left panel) and 2 (right panel).

winner and the runner-up was quite large in most of the cases, and incumbent candidates have been all confirmed. It could be that pre-existing expectations about the elections results may have mitigated the effect on the respondents' concern about the pandemic. Finally, one could also argue that the relevance of the regional administration for the health care policy was not clear to all voters. This is something that we cannot control for in this study. However, we believe that in September 2020, about six months into the pandemic crisis, Italian citizens were exposed to this piece of information time and time again.

\section{CONCLUSIONS}

This study aimed at providing further understanding of the ways in which partisanship is able to affect several aspects of citizens' lives and beliefs. Recent literature on the topic is fairly consensual in this respect: partisanship is a strong factor affecting citizens' attitudes in a variety of domains, political and non-political. Coherently, several studies have demonstrated that partisanship has been effective in shaping attitudes during the pandemic (e.g., Druckman et al., 2020; Hornsey et al., 2020). In this paper we contend that an election could be conceived as a competition between different worldviews, proposals, and loyalty structures (Anderson et al., 2005). Once citizens vote for a certain party/leader, they have a number of (rational and emotional) expectations on the outcome of the election. Therefore, having voted for the winning/ losing party or candidate may affect the expectations that one had before the election. This argument is supported by previous research on the effect that electoral winner/ loser status has on economic views. Findings have shown that voters of losing candidates tend to perceive in a more pessimist way the future economic performance of their country with respect to those supporting winning candidates (see Quaranta et al., 2020).

By using panel survey data collected before and after Italian regional elections in September 2020, we assessed whether winner/loser status can affect people's view with respect to the COVID-19 pandemic crisis. We focused on this aspect for two main reasons. First, we maintain that the impact of winner/loser status can be applied to a larger bouquet of attitudes and behaviors, as the mechanisms driving the empirical evidence collected so far are quite general. Second, the second-order elections frame- 
work should be applied cautiously when referring to 2020 Italian regional elections (Reif and Schmitt, 1980). We argue that the regional competitions had a lot at stake in 2020, given the pivotal role played by regional governments in handling the COVID-19 emergency. As regions are entitled to manage the health matters, who wins the regional elections is also responsible (and accountable) for the public health system in that territory, and thus for the measures and policies issued in response to the emergency. In short, if being a regional president is not trivial at ordinary times, it is even less in times of pandemic. The longitudinal results presented partially confirm our hypotheses. Indeed, we find that losers tend not to improve their perceived societal risk, while both winners and people in the control group (respondents living in those regions where regional elections were not held) do. This suggests that while all Italians were becoming more optimistic in that period, electoral losers did not. On the other hand, we do not identify significant differences between winners and losers for what concerns individual risk perceptions. This is somewhat consistent with previous studies that did not assess any relevant difference based on the electoral status in predicting individual economic outcomes.

In sum, and to conclude, this study contributed to the literature investigating the differences among winners and losers of an election, by extending the scope of this research beyond the classical economic dimension. With regard to the contribution to the literature of our work, findings demonstrate that electoral status is relevant in shaping attitudes and behaviors in a broad set of cases, and even in situations in which party cues might be hypothesized to be disregarded. This is the reason why investigating these mechanisms during the COVID-19 pandemic represents an extremely interesting case study in this respect. Likewise, these results - based on a non-US sample - could also contribute to a better understanding of citizens' attitudes towards vaccines or other restriction measures.

\section{ACKNOWLEDGEMENTS:}

All authors contributed equally. The authors wish to thank the special issue editors as well as two anonymous reviewers for their helpful comments.

\section{REFERENCES}

Allcott, H., Boxell, L., Conway, J., Gentzkow, M., Thaler, M., \& Yang, D. (2020). Polarization and public health: Partisan differences in social distancing during the coronavirus pandemic. Journal of Public Economics, 191, 104254.

Anderson, C. J., \& Guillory, C. A. (1997). Political institutions and satisfaction with democracy: A crossnational analysis of consensus and majoritarian systems. American Political Science Review, 91(1), 66-81.

Anderson, C. J., Blais, A., Bowler, S., Donovan, T., \& Listhaug, O. (2005). Losers' consent: Elections and democratic legitimacy. Oxford: Oxford University Press.

Barrios, J.M., Hochberg Y.V. (2020). Risk Perception Through the Lens of Politics in the Time of the COVID-19 Pandemic, BFI WORKING PAPER, University of Chicago

Barrios, J. M., Benmelech, E., Hochberg, Y. V., Sapienza, P., \& Zingales, L. (2021). Civic capital and social distancing during the Covid-19 pandemic. Journal of public economics, 193, 104310.

Baumeister, R. F., Bratslavsky, E., Finkenauer, C., \& Vohs, K. D. (2001). Bad is stronger than good. Review of General Psychology, 5(4), 323-370.

Bisgaard, M. (2015). Bias will find a way: Economic perceptions, attributions of blame, and partisan-motivated reasoning during crisis. The Journal of Politics, $77(3), 849-860$.

Blais, A., \& Gélineau, F. (2007). Winning, losing and satisfaction with democracy. Political Studies, 55(2), 425-441.

Bolgherini, S., and Grimaldi, S. (2017). Critical election and a new party system: Italy after the 2015 regional election. Regional \& Federal Studies, 27(4): 483-505.

Calvillo, D. P., Ross, B. J., Garcia, R. J., Smelter, T. J., \& Rutchick, A. M. (2020). Political ideology predicts perceptions of the threat of covid-19 (and susceptibility to fake news about it). Social Psychological and Personality Science, 11(8), 1119-1128.

Chang, E, Chu, Y-h, Wu, W-c (2014) Consenting to lose or expecting to win? Inter-temporal changes in voters' winner-loser status and satisfaction with democracy. In: Thomassen, J (Ed.) Elections and Representative Democracy: Representation and Accountability. Oxford: Oxford University Press, pp. 232-253.

Dahlberg, S., \& Linde, J. (2017). The dynamics of the winner-loser gap in satisfaction with democracy: Evidence from a Swedish citizen panel. International Political Science Review, 38(5), 625-641.

Dandoy, R., \& Schakel, A. (Eds.). (2013). Regional and national elections in Western Europe: Territoriality of the vote in thirteen countries. London: Springer.

De Sio, L. (2020). Numeri e dati alla mano, ecco alcuni messaggi contenuti nel voto degli Italiani per Regioni e referendum, Policy Brief n. 09/2020. Luiss University. 
Druckman, J. N., Klar, S., Krupnikov, Y., Levendusky, M., \& Ryan, J. B. (2020). How Affective Polarization Shapes Americans' Political Beliefs: A Study of Response to the COVID-19 Pandemic. Journal of Experimental Political Science, 8(3), 223-234.

Enns, P. K., Kellstedt, P. M., \& McAvoy, G. E. (2012). The consequences of partisanship in economic perceptions. Public Opinion Quarterly, 76(2), 287-310.

Gollwitzer, A., Martel, C., Brady, W. J., Pärnamets, P., Freedman, I. G., Knowles, E. D., \& Van Bavel, J. J. (2020). Partisan differences in physical distancing are linked to health outcomes during the COVID-19 pandemic. Nature human behaviour, 4(11), 1186-1197.

Graham, A., Cullen, F. T., Pickett, J. T., Jonson, C. L., Haner, M., \& Sloan, M. M. (2020). Faith in Trump, moral foundations, and social distancing Defiance during the coronavirus pandemic. Socius, 6, 2378023120956815.

Grossman, G., Kim, S., Rexer, J. M., \& Thirumurthy, H. (2020). Political partisanship influences behavioral responses to governors' recommendations for COVID-19 prevention in the United States. Proceedings of the National Academy of Sciences, 117(39), 2414424153.

Hansen, S. W., Klemmensen, R., \& Serritzlew, S. (2019). Losers lose more than winners win: Asymmetrical effects of winning and losing in elections. European Journal of Political Research, 58(4), 1172-1190.

Hill, T., Gonzalez, K. E., \& Davis, A. (2020). The Nastiest Question: Does Population Mobility Vary by State Political Ideology during the Novel Coronavirus (COVID-19) Pandemic?. Sociological perspectives, 64(5), 786-803.

Hornsey, M. J., Finlayson, M., Chatwood, G., \& Begeny, C. T. (2020). Donald Trump and vaccination: The effect of political identity, conspiracist ideation and presidential tweets on vaccine hesitancy. Journal of Experimental Social Psychology, 88, 103947.

Kreps, S., Prasad, S., Brownstein, J. S., Hswen, Y., Garibaldi, B. T., Zhang, B., \& Kriner, D. L. (2020). Factors associated with US adults' likelihood of accepting COVID-19 vaccination. JAMA network open, 3(10).

Kunda, Z. (1990). The case for motivated reasoning. Psychological Bulletin, 108(3), 480-498.

Lau, R. R., \& Redlawsk, D. P. (2001). Advantages and disadvantages of cognitive heuristics in political decision making. American Journal of Political Science, 45(4), 951-971.

Leeper, T. J., \& Slothuus, R. (2014). Political parties, motivated reasoning, and public opinion formation. Advances in Political Psychology, 35(1), 129-156.
Lewis-Beck, M. S., Nadeau, R., \& Elias, A. (2008). Economics, party, and the vote: Causality issues and panel data. American Journal of Political Science, 52(1), 84-95.

Lupia, A., \& McCubbins, M. D. (1998). The democratic dilemma: Can citizens learn what they need to know? Cambridge: Cambridge University Press.

Mancosu, M., \& Vezzoni, C. (2018). Local and national effects in the electoral cycle: the case of Italy (20012009). Territory, Politics, Governance, 6(3), 381-399.

Martini, S., \& Quaranta, M. (2015). Finding out the hard way: Uncovering the structural foundations of political dissatisfaction in Italy, 1973-2013. West European Politics, 38(1), 28-52.

Martini, S., \& Quaranta, M. (2019). Political support among winners and losers: Within-and betweencountry effects of structure, process and performance in Europe. European Journal of Political Research, 58(1), 341-361.

Massetti, E. (2018). Regional elections in Italy (2012-15): Low turnout, tri-polar competition and Democratic Party's (multi-level) dominance. Regional \& Federal Studies, 28(3): 325-351.

Massetti, E., and Sandri, G. (2013). Italy: between growing incongruence and region-specific dynamics. In R. Dandoy and A. Schakel, A. (Eds.). Regional and national elections in Western Europe: Territoriality of the vote in thirteen countries. London: Palgrave Macmillan, pp. 142-161.

Nuti, S., \& Seghieri, C. (2014). Is variation management included in regional healthcare governance systems? Some proposals from Italy. Health policy, 114(1), 71-78.

Painter, M., \& Qiu, T. (2021). Political beliefs affect compliance with government mandates. Journal of Economic Behavior \& Organization, 185, 688-701.

Quaranta, M., Mancosu, M., \& Martini, S. (2020). A Tale of Bias: Longitudinal Evidence of the Effect of Electoral Defeat on Citizens' Evaluations of the Economy. International Journal of Public Opinion Research, 32(3), 604-620.

Reif, K., \& Schmitt, H. (1980). Nine second-order national elections-a conceptual framework for the analysis of European Election results. European Journal of Political Research, 8(1), 3-44.

Riganti, A. (2021). Containing costs in the Italian local healthcare market. Health Economics, 30(5), 10011014.

Schakel, A. \& Romanova, V. (2018) Towards a scholarship on regional elections. Regional \& Federal Studies, 28(3), 233-252.

Schakel, A. H., \& Jeffery, C. (2013). Are regional elections really 'second-order' elections?. Regional studies, 47(3), 323-341. 
Soroka, S. N. (2014). Negativity in democratic politics: Causes and consequences. Cambridge: Cambridge University Press.

Taber, C. S., \& Lodge, M. (2006). Motivated skepticism in the evaluation of political beliefs. American Journal of Political Science, 50(3), 755-769.

Tronconi, F. (2015). Bye-bye bipolarism: the 2015 regional elections and the new shape of regional party systems in Italy. South European Society and Politics, 20(4), 553-571.

Tronconi, F., \& Roux, C. (2009). The political systems of Italian regions between state-wide logics and increasing differentiation. Modern Italy, 14(2), 151-166.

Vampa, D. (2021a). The 2020 regional elections in Italy: sub-national politics in the year of the pandemic. Contemporary Italian Politics, 13(2), 166-180.

Vampa, D. (2021b). COVID-19 and Territorial Policy Dynamics in Western Europe: Comparing France, Spain, Italy, Germany, and the United Kingdom. Publius, the Journal of Federalism, 51(4), 601-626.

Vampa, D. (2015). The 2015 regional election in Italy: fragmentation and crisis of subnational representative democracy. Regional \& Federal Studies, 25(4): 365-378.

Ward, J. K., Alleaume, C., Peretti-Watel, P., the COCONEL Group (2020). The French public's attitudes to a future COVID-19 vaccine: The politicization of a public health issue. Social science \& medicine, 265, 113414.

Wooldridge, J. M. (2013). Introductory econometrics: A modern approach. (5th ed.). Mason, IA: South-Western. 


\section{SUPPLEMENTARY MATERIAL}

Table A1. Two multilevel regression models studying individual and societal pandemic risk in the future (with referendum vote as a control).

\begin{tabular}{|c|c|c|c|c|}
\hline \multirow{2}{*}{$\begin{array}{l}\text { Dep. variable } \\
\text { Indep. Variables }\end{array}$} & \multicolumn{2}{|c|}{$\begin{array}{l}\text { Model } 1 \text { - Alt } \\
\text { Societal }\end{array}$} & \multicolumn{2}{|c|}{$\begin{array}{l}\text { Model } 2 \text { - Alt } \\
\text { Individual }\end{array}$} \\
\hline & Coef. & S.E. & Coef. & S.E. \\
\hline \multicolumn{5}{|l|}{ Electoral status (ref. Loser) } \\
\hline No regional election held & $-0.31^{\star *}$ & $(0.13)$ & $-0.20^{*}$ & $(0.10)$ \\
\hline Winner & $-0.34^{\star *}$ & $(0.14)$ & -0.16 & $(0.12)$ \\
\hline Gender: Woman (ref. Man) & 0.01 & $(0.08)$ & 0.06 & $(0.07)$ \\
\hline Age & 0.00 & $(0.00)$ & 0.00 & $(0.00)$ \\
\hline \multicolumn{5}{|l|}{ Education level (ref. Primary) } \\
\hline Secondary & -0.09 & $(0.13)$ & $-0.21^{*}$ & $(0.11)$ \\
\hline Tertiary & -0.11 & $(0.14)$ & -0.17 & $(0.12)$ \\
\hline \multicolumn{5}{|c|}{ Municipality size (ref. Under 10k) } \\
\hline $10 \mathrm{k}-100 \mathrm{k}$ & $0.20^{\star}$ & $(0.11)$ & 0.06 & $(0.09)$ \\
\hline Over 100k & $0.25^{\star *}$ & $(0.11)$ & 0.00 & $(0.09)$ \\
\hline \multicolumn{5}{|c|}{ Left-right self-placement (ref. Left) } \\
\hline Center-left & 0.16 & $(0.13)$ & 0.02 & $(0.11)$ \\
\hline Center & $0.36^{\star *}$ & $(0.17)$ & -0.04 & $(0.14)$ \\
\hline Center-right & 0.13 & $(0.14)$ & 0.11 & $(0.12)$ \\
\hline Right & 0.23 & $(0.17)$ & 0.15 & $(0.14)$ \\
\hline Not located & 0.10 & $(0.18)$ & -0.07 & $(0.15)$ \\
\hline Interest in politics & $0.13^{\star \star}$ & $(0.06)$ & 0.07 & $(0.05)$ \\
\hline $\begin{array}{l}\text { Party identification (ref. not } \\
\text { identified) }\end{array}$ & 0.00 & $(0.10)$ & -0.13 & $(0.08)$ \\
\hline $\begin{array}{l}\text { Working conditions (ref. } \\
\text { Employed) }\end{array}$ & $0.17^{\star \star}$ & $(0.08)$ & 0.02 & $(0.07)$ \\
\hline \multicolumn{5}{|c|}{ Geo-political zone (ref. North-West) } \\
\hline North-East & 0.03 & $(0.11)$ & -0.08 & $(0.09)$ \\
\hline Center & -0.01 & $(0.12)$ & 0.12 & $(0.10)$ \\
\hline South & -0.10 & $(0.12)$ & -0.07 & $(0.10)$ \\
\hline Islands & 0.02 & $(0.14)$ & -0.11 & $(0.11)$ \\
\hline \multicolumn{5}{|l|}{ Referendum vote (ref. Yes) } \\
\hline No & 0.04 & $(0.09)$ & -0.02 & $(0.07)$ \\
\hline NV/NA & $0.23^{* *}$ & $(0.12)$ & 0.06 & $(0.09)$ \\
\hline Constant & $-0.93^{* * *}$ & $(0.33)$ & -0.06 & $(0.27)$ \\
\hline Lvl-2 var & $0.00^{* * *}$ & $(0.00)$ & $0.00^{* * *}$ & $(0.00)$ \\
\hline Lvl-1 var & $1.91^{\star * *}$ & $(0.03)$ & $1.89^{\star * *}$ & $(0.03)$ \\
\hline Observations & 2,484 & 2,349 & & \\
\hline Number of groups & 20 & 20 & & \\
\hline
\end{tabular}

Standard errors in parentheses. ${ }^{* *} \mathrm{p}<0.01,{ }^{* *} \mathrm{p}<0.05,{ }^{*} \mathrm{p}<0.1$.
Table A2. Descriptive statistics.

\begin{tabular}{lcccc}
\hline Variable & Min & Mean & Max & S.D. \\
\hline Societal risk & -9 & -0.34 & 9 & 1.9 \\
Individual risk & -8 & -0.14 & 7 & 1.6 \\
\hline Electoral status: No regional election & 0 & 0.75 & 1 & 0.44 \\
held & 0 & 0.15 & 1 & 0.35 \\
Winner & 0 & 0.11 & 1 & 0.31 \\
Loser & 1 & 1.5 & 2 & 0.5 \\
\hline Gender (ref. Male) & 18 & 51 & 90 & 17 \\
\hline Age & 0 & 0.11 & 1 & 0.31 \\
\hline Education level: low & 0 & 0.46 & 1 & 0.5 \\
Medium & 0 & 0.43 & 1 & 0.5 \\
High & 0 & 0.2 & 1 & 0.4 \\
\hline Municipality size: Under 10k & 0 & 0.43 & 1 & 0.5 \\
10k - 100k & 0 & 0.37 & 1 & 0.48 \\
Over 100k & 0 & 0.11 & 1 & 0.31 \\
\hline Left-right self-placement: Left & 0 & 0.32 & 1 & 0.47 \\
Center-left & 0 & 0.11 & 1 & 0.31 \\
Center & 0 & 0.25 & 1 & 0.43 \\
Center-right & 0 & 0.093 & 1 & 0.29 \\
Right & 0 & 0.12 & 1 & 0.33 \\
Not located & 0 & 0.76 & 1 & 0.43 \\
\hline Party identification (ref. not identified) & 1 & 2.9 & 4 & 0.77 \\
\hline Interest in politics & 0 & 0.28 & 1 & 0.45 \\
\hline Geo-political zone: North-West & 0 & 0.19 & 1 & 0.39 \\
North-East & 0 & 0.18 & 1 & 0.39 \\
Center & 0 & 0.23 & 1 & 0.42 \\
Islands & 0 & 0.11 & 1 & 0.32 \\
\hline Working conditions (ref. Employed) & 1 & 1.5 & 2 & 0.5 \\
\hline
\end{tabular}

